\title{
Concentrate for Emulsion for Infusion Dosage Form
}

National Cancer Institute

\section{Source}

National Cancer Institute. Concentrate for Emulsion for Infusion Dosage Form. NCI

Thesaurus. Code C149390.

Liquid sterile preparation intended to be diluted in the specified liquid to obtain an

emulsion for infusion. 